Article

\title{
Highest Cost First-Based QoS Mapping Scheme for Fiber Wireless Architecture
}

\author{
Khalid.H. Mohammadani ${ }^{1, *(\mathbb{D})}$, Rizwan Aslam Butt ${ }^{2}{ }^{\mathbb{D}}$, Kamran Ali Memon ${ }^{3} \mathbb{D}$, Fayaz Hassan ${ }^{4}$, \\ Abdul Majeed ${ }^{4}$ and Rajesh Kumar ${ }^{5}$ (D) \\ 1 State Key Laboratory of Information Photonics and Optical Communications, School of Electronic \\ Engineering, Beijing University of Posts and Telecommunications, Beijing 100876, China \\ 2 Department of Electronic Engineering, NED University of Engineering, Karachi 75270, Pakistan; \\ rizwan.aslam@neduet.edu.pk \\ 3 Department of Electronic Engineering, QUEST, Nawabshah 67450, Pakistan; alikamran77@quest.edu.pk \\ 4 School of Electronic Engineering, Beijing University of Posts and Telecommunications, Beijing 100876, China; \\ fayaz.hassan@bupt.edu.cn (F.H.); majeed@bupt.edu.cn (A.M.) \\ 5 School of Computer science and Technology, Beijing Institute of Technology, Beijing 100876, China; \\ rajesh93_kh@live.com \\ * Correspondence: wangkhm@bupt.edu.cn; Tel.: +86-156-0022-9218
}

Received: 8 October 2020; Accepted: 8 November 2020; Published: 22 November 2020

\begin{abstract}
The combination of a high-speed wireless network with passive optical network technologies has led to the evolution of a modern integrated fiber wireless (FiWi) access network. Compared to broadband wireless networks, the FiWi network offers higher bandwidth with improved reliability and reduced maintenance costs due to the passive nature of passive optical network (PON). Since the quality of service (QoS) is a baseline to deploy high-speed FiWi broadband access networks, therefore, it is essential to analyze and reduce the typical problems (e.g., bandwidth and delay) in the high-speed next-generation networks (NGANs). This study investigates the performance of a fiber wireless architecture where a 10-Gigabit-capable passive optical network (XGPON) and fifth generation of wireless local area network (WLAN) (i.e., IEEE 802.11ac) are integrated. Both technologies take benefits from each other and have pros and cons concerning the QoS demands of subscribers. The proposed work offers a very flexible QoS scheme for the different types of services of 5G WLAN and XGPON with the help of the highest cost first (HCF) algorithm, which leads to reduced upstream delays for delay-sensitive applications. The simulation results show that the HCF algorithm boosts the performance of the dynamic bandwidth assignment (DBA) scheme and results in up to $96.1 \%, 90.8 \%$, and $55.5 \%$ reduced upstream (US) delays for video: VI(T2), background: BK(T3), and best effort: $\mathrm{BE}(\mathrm{T} 4)$ traffic in enhanced-distributed-channel-access (EDCA) mode. Compared to earlier work, the HCF and immediate allocation with the colorless grant (IACG) DBA combination results in the reduction of up to $54.8 \%$ and $53.4 \%$ mean US delays. This happens because of $50 \%$ to $65 \%$ better bandwidth assignment by the IACG DBA process due to efficient mapping by the HCF algorithm.
\end{abstract}

Keywords: FiWi access network; QoS mapping; XGPON; 802.11ac; DCF; EDCA; 5G-WLAN; QoS; US Traffic

\section{Introduction}

With the rapid increase in bandwidth-hungry applications, Internet devices, and the emergence of online business and gaming, the demand for high-speed internet with mobility is continuously growing [1]. The requirement of mobility and higher bandwidth at the same time requires the integration of wired and wireless broadband technologies. Deployment of wireless technology integrated with next-generation passive optical networks (NG-PON) to achieve this task is an attractive solution that 
meets both of these requirements efficiently. The wireless network is a community of portable devices that is nowadays a key enabling technology for the mobile ad-hoc network [2,3], Internet of things (IoT), and 5G [4,5]. These devices communicate via access points (APs) or base stations [6]. Optical fiber technology builds a high-speed data communication network that connects these APs with the Mobile switching center (MSC), Internet Service Provider (ISP), and the Video Headend. Typically, wireless local area network (WLAN) and passive optical network (PON) are different types of access networks with different bandwidth and quality of service (QOS) requirements. On the other hand, over the past few years, the passive optical network (PON) has emerged as the most attractive choice for network providers offering broadband services. The PON is a point to multipoint (P2MP) optical access network, it contains an Optical Line Terminal (OLT), passive Splitter, and multiple Optical Network Units (ONUs). PON offers huge bandwidth support in addition to being a low-cost access network solution for the provisioning of broadband services $[7,8]$. In the PON, the signal distribution among output devices, each receiver receives a separate signal for a separate QoS service. Each ONU in PON sends signals to a central distribution point called OLT, allowing users to share the transmission capacity of the entire system in a coordinated manner.

Fiber wireless (FiWi) access network is a hybrid network of both of these access networks, where optical fiber technology and wireless technology work together in collaboration. Such a network is also termed as a fronthual network in the $5 \mathrm{G}$ context. Typically, mobile operators charge subscribers on a per-byte basis for using the Internet due to their licensed frequency band [9]. However, due to the license-free frequency band, a Wi-Fi (IEEE 802.11) connection is inexpensive as it is charged on a bandwidth subscription basis only. IEEE 802.11 standard is widely used for WLAN infrastructure as it is flexible and easy to install for different environmental conditions (i.e., home, outdoor, hot spot, enterprise, metropolitan area, etc.), and it requires lower maintenance cost compared to a conventional cellular wireless network.

Initially, IEEE 802.11 supported only the best-effort traffic [10], however, the latest version, IEEE 802.11ac, supports QoS applications as well [11]. This version, IEEE 802.11ac, provides very high throughput (VHT) and high internet speed for multimedia services with the help of multiple-input multiple-output (MIMO) techniques [12,13] and is also known as the 5th generation of Wi-Fi (5G Wi-Fi). The IEEE 802.11ac medium access control (MAC) offers a different range of access modes, namely, distributed-coordination function (DCF) and enhanced distributed-channel access (EDCA), Point CF (PCF), and hybrid coordination function (HCF) and HCF controlled Channel Access (HCCA). HCCA and EDCA access modes differentiate among different traffic/data classes such as voice, video, best effort, and background, with different traffic class priorities. These access modes suffer from the intra-node fairness issue that arises when wireless channel access is completely occupied by high-priority traffic. Consequently, minimum channel access is spared for the low-priority traffic, which indicates the unfair utilization of channel resources [14,15].

Typically, there are two categories of the FiWi access network that can be mainly divided into two categories according to network architecture: one is integrated wireless-optical mesh networking and the other one is the integration of wireless-optical access networking [16]. This paper focuses on the second category, i.e., integration of wireless-optical access networking. The proposed work presents a novel QoS mapping algorithm between XGPON and fifth-generation WLAN in the FiWi access network. Further, immediate allocation with the colorless grant (IACG) DBA is used for XGPON upstream bandwidth distribution among the ONUs, and two wireless channel distribution schemes are used in the fifth-generation WLAN side to explore an appropriate WLAN wireless scheme for FiWi access network. We have compared IACG DBA with deficit X-GigaPON Access Network (DXGIANT) DBA and identified more effective XGPON DBA for the FiWi access network.

The rest of this paper is organized as follows: Section 2 describes a brief overview of the related work with the FiWi access network. Section 3 explains in detail the distributed channel schemas of 802.11ac and XG-PON. In Section 4, the proposed mapping schemas have been described for FiWi. In 
Section 5, simulation setup and results are presented with full discussion. Finally, Section 6 concludes the paper.

\section{Related Work}

In the literature, the wireless-fiber integration technology has been implemented with different wireless technologies, such as WiMax, WLAN, and Long Term Evolution (LTE). However, the key requirement of any of the implementation is to guarantee the QoS. In most of the studies, a standalone architecture comprising of Ethernet Passive Optical Network (EPON) and WiMAX has remained in focus. For example, the study in Reference [17] introduced the policy of minimum best effort (MBE), where all services are granted the minimum bandwidth. The dynamic allocation takes into account QoS and traffic arrival rates and treats the bandwidth requests using a real-time polling service/assured forwarding (PS/AF) policy. In another similar study, the authors of Reference [18] demonstrated a new generation broadband network and proposed four integrated architectures based on the integration of WiMAX and EPON to reduce operational costs in a fixed-mobile converged (FMC) network. An integrated WiMAX-EPON network approach for the same standalone architecture with extended coverage was demonstrated in Reference [19]. The proposed architecture uses an intermediate sub-network of OLTs between the normal configuration of OLT and ONUs. This sub-OLT handles the networking issues in the backhaul and the front-end. Using LTE capability to work with a high data rate, the convergence of EPON and LTE technologies have been implemented for possible FiWi networks [20]. Another FiWi network has been designed with a combination of wireless sensor networks (WSNs) and EPON, known as fiber wireless sensor network (Fi-WSN) [21]. This cross-layer service mechanism is designed to reduce processing delay at ONUs for smart grid applications. Researchers envisage the use of different GPON DBA algorithms in the context of XGPON fiber to the antenna, where the fiber optic terminates at the base station of the LTE network as backhaul, and they have also proposed a deficit XGIANT DBA for the XGPON network [22]. A testbed was designed for an integrated GPON-WiMAX architecture, where GPON was used as a backhaul with WiMAX as a front-haul [23]. They designed a mapping among the traffic classes of GPON and traffic class of the WiMAX network according to the respective QoS standards. The study in Reference [24] presented the QoS mapping policy for the pairs of ONU-evolved Node-B (ONU-eNB) for LTE/EPON networks. In this policy, each LTE packet was stamped with the inimitable Differentiated Services Code Point (DSCP) values and then sent to ONU. A single FIFO queue performs all to one mapping and each DSCP is set for the class of service (CoS) to ensure an easy QoS mapping for the ONU-eNB ONU. This DSCP-to-CoS preset takes the place of packet classification in the ONU, encouraging the minimal loading of the packet classification. A QoS-aware integration of the XG-PON and Wi-Fi network was designed in Reference [25] to provide e-services to subscribers. Authors have used the DXGIANT DBA algorithm at the XGPON side and the EDCA model at wireless local area network with IEEE 802.11n. IEEE $802.11 \mathrm{n}$ is the $4 \mathrm{G}$ Wi-Fi standard [26]. They observed that the low-priority traffic suffered from bandwidth starvation, making the network unfair for the best-effort traffic due to a high transmission opportunity (TXOP) period and contention window (CW) time in EDCA. Therefore, they focused on modification of the TXOP and the CW parameters. They claimed that they achieved more fairness for low-priority traffic in their FiWi scenario. A hierarchical QoS-aware DBA (HQA-DBA) algorithm has been proposed for the surplus sharing policy in Reference [27]. The proposed DBA algorithm supports the fairness of bandwidth for assigning bandwidth to users according to its QoS requirements and based on priority queue weight. The authors proposed two DBA schemes that run separately in OLT and OBF (ONU-BS facility). Both DBA algorithms are responsible for the appropriate allocation of bandwidth in their respective domain. The authors of Reference [28] suggested some suitable schemes (i.e., idle sense (IS) and Asymmetric Access Point (AAP)) to improve the performance of the FiWi network with the help of GPON downstream information. Table 1 shows different existing integrated fiber wireless architectures that have been proposed in the literature to achieve different QoS goals. 
Table 1. Comparison of FiWi networks.

\begin{tabular}{|c|c|c|c|c|c|}
\hline Proposed & $\begin{array}{l}\text { Wireless } \\
\text { Technology }\end{array}$ & $\begin{array}{c}\text { PON } \\
\text { Technology }\end{array}$ & Implementation Goal & Pros & Cons \\
\hline $\begin{array}{l}\text { WiMAX-EPON } \\
\text { Network (WEN) and } \\
\text { WE-DBA [17] }\end{array}$ & $\begin{array}{l}\text { WiMAX and IEEE } \\
\quad 802.16\end{array}$ & EPON & $\begin{array}{l}\text { Solve bandwidth fairness issue at virtual } \\
\text { ONU and WiMAX STA }\end{array}$ & Support BE application & $\begin{array}{l}\text { Less reliable for other } \\
\text { applications }\end{array}$ \\
\hline $\begin{array}{l}\text { Integration of EPON } \\
\text { and WiMAX for FMC } \\
\qquad[18]\end{array}$ & WiMAX & EPON & $\begin{array}{l}\text { To solve operational issues of fixed } \\
\text { mobile convergence (FMC) }\end{array}$ & Low operational costs & $\begin{array}{l}\text { No support to dynamic } \\
\text { convergence }\end{array}$ \\
\hline $\begin{array}{c}\text { Integrated } \\
\text { WiMAX-EPON } \\
\text { networks and DBA } \\
{[19]}\end{array}$ & WiMAX IEEE 802.16 & EPON & $\begin{array}{c}\text { Architecture based on } \\
\text { optical-optical-wireless (OOW) network. } \\
\text { And DBA runs at BS, ONU, and OLT in } \\
\text { OOW. }\end{array}$ & Extends coverage area & Delay > $50 \mathrm{~ms}$ \\
\hline $\begin{array}{l}\text { The convergence of } \\
\text { EPON and LTE [20] }\end{array}$ & LTE & EPON & $\begin{array}{c}\text { FiWi architecture was designed based on } \\
\text { LTE and EPON to solve the problem of } \\
\text { a high data rate. }\end{array}$ & Support high bandwidth & High operational cost \\
\hline $\begin{array}{l}\text { Fiber wireless sensor } \\
\text { network (Fi-WSN) [21] }\end{array}$ & IEEE 802.15.4 & EPON & $\begin{array}{l}\text { Evaluate a QoS mapping for the Fi-WSNs } \\
\text { for delay-critical smart grid applications. }\end{array}$ & $\begin{array}{l}\text { Reduce high-priority } \\
\text { traffic delay }\end{array}$ & $\begin{array}{l}\text { Low-priority traffic } \\
\text { starvation }\end{array}$ \\
\hline $\begin{array}{l}\text { The convergence of } \\
\text { XG-PON and LTE } \\
\text { with two DBAs [22] }\end{array}$ & LTE & XG-PON & $\begin{array}{l}\text { Proposed optimized DBAs for converged } \\
\text { network }\end{array}$ & Fair QoS for TCP traffic & $\begin{array}{l}\text { Less effective for UDP } \\
\text { traffic }\end{array}$ \\
\hline $\begin{array}{l}\text { A control bridge for } \\
\text { Integration of GPON } \\
\text { with WiMAX [23] }\end{array}$ & WiMAX & XG-PON & $\begin{array}{l}\text { To keep dynamic QoS specification for } \\
\text { converged network }\end{array}$ & Reduce data delivery cost & More network complexity \\
\hline $\begin{array}{c}\text { QoS provisioning } \\
\text { scheme for LTE/EPON } \\
\text { [24] }\end{array}$ & LTE & EPON & $\begin{array}{l}\text { The proposed plan improves the overall } \\
\text { flow of CBR traffic by } 40 \% \text {. }\end{array}$ & Support CBR traffic & No support to VBR traffic \\
\hline $\begin{array}{l}\text { Integrated XGPON } \\
\text { with EDCA [25] }\end{array}$ & IEEE 802.11n & XGPON & $\begin{array}{c}\text { Resource allocation in the integrated } \\
\text { network }\end{array}$ & $\begin{array}{l}\text { Fair QoS support for IP } \\
\text { traffic }\end{array}$ & $\begin{array}{l}\text { Not suitable for CBR } \\
\text { application }\end{array}$ \\
\hline $\begin{array}{c}\text { Idle sense (IS) and } \\
\text { asymmetric AP for } \\
\text { FiWi [28] }\end{array}$ & IEEE 802.11b & GPON & $\begin{array}{l}\text { Improve the fairness issue in wireless } \\
\text { users }\end{array}$ & DCF support & No EDCA support \\
\hline
\end{tabular}


The brief literature review above validates the argument that the integration of PON with various wireless access networks offers a promising solution for the broadband access technology in terms of higher gain in bandwidth capacity, less delay, and minimal cost of operation. However, the ITU-T compliant PON and the IEEE compliant Wi-Fi standards support different protocol architecture and have QOS compatibility problems. Some of the existing work has been done with QoS mapping and provisioning for independent and hybrid architectures of the integrated fiber wireless access network $[17,18,23]$ to offer different services. Previous work failed to focus on the adequate quality of services for the fifth generation fiber wireless access network. In fact, it is a challenging task to meet the QoS requirements of the compact architecture; therefore, the suitable QoS mapping issue is still an open research area, particularly in a converged network. The present paper aims to design a QoS mapping architecture for the FiWi access network with the help of the highest cost first (HCF) algorithm and investigates delay-sensitive QoS services of integrated fiber wireless access networking, where the optical network unit (ONU) is directly connected to a wireless domain through a wireless access point (WAP) that assists wireless communication between subscribers and the network. Moreover, this paper also analyzes the fairness issue using DCF and EDCA of IEEE 802.11ac along with multimedia traffic in the FiWi access network.

\section{Distributed Channel Schemas of 802.11ac and XGPON}

When the data packets arrive at the MAC layer of a wireless station (STA) from upper layers, the STA executes either the DCF or EDCA channel distributed method to transmit packets on the wireless medium. DCF is a basic distributed scheme of 802.11ac that uses the Carrier Sense Multiple Access mechanisms with Collision Avoidance (CSMA/CA). A collision of transmission can occur when multiple nodes want to access channels simultaneously, therefore DCF uses the CA mechanism to control the collisions between transmissions. Figure 1 presents a basic flowchart of the DCF model. In DCF, the STA detects distributed inter-frame spacing (DIFS) before accessing the wireless channel [29]. When the wireless medium is not busy, the STA transmits frames directly to the wireless medium without waiting for the time-period termed as back-off time $\left(\mathrm{T}_{\mathrm{BO}}\right)$, resulting in a delay of transmission of a random time-period, $\mathrm{T}_{\mathrm{BO}}$. A value of the $\mathrm{T}_{\mathrm{BO}}$ is uniformly obtained using Equation (1), where the $\mathrm{R}_{\text {Counter }}$, known as back-off (BO) random counter, is chosen between zero and CW-1 using Equation (2), and $\mathrm{T}_{\text {Slot }}$ is the Slot-Time parameter for the $\mathrm{BO}$ process. In case of unsuccessful transmission, STA repeats the BO process and the size of $\mathrm{CW}$ by a factor of $2^{\mathrm{N}}-1$ in each re-transmission up to the maximum contention window ( $\left.\mathrm{CW}_{\text {Max }}\right)$ size, following Equation (3) [30]. $\mathrm{CW}$ is reset to the minimum contention window $\left(\mathrm{CW}_{\mathrm{Min}}\right)$ when the transmission is repeated up to a specific retry limit time or when the transmission is successful [31]. Figure 1 explains this process step by step using a flowchart.

$$
\begin{gathered}
\mathrm{T}_{\mathrm{BO}}=\mathrm{R}_{\text {Counter }} \times \mathrm{T}_{\text {Slot }} \\
\mathrm{R}_{\text {Counter }}=\text { Pseudorandom }[0, \mathrm{CW}-1] \\
\mathrm{CW}_{\mathrm{Min}} \leq \mathrm{CW} \leq \mathrm{CW}_{\mathrm{Max}}
\end{gathered}
$$




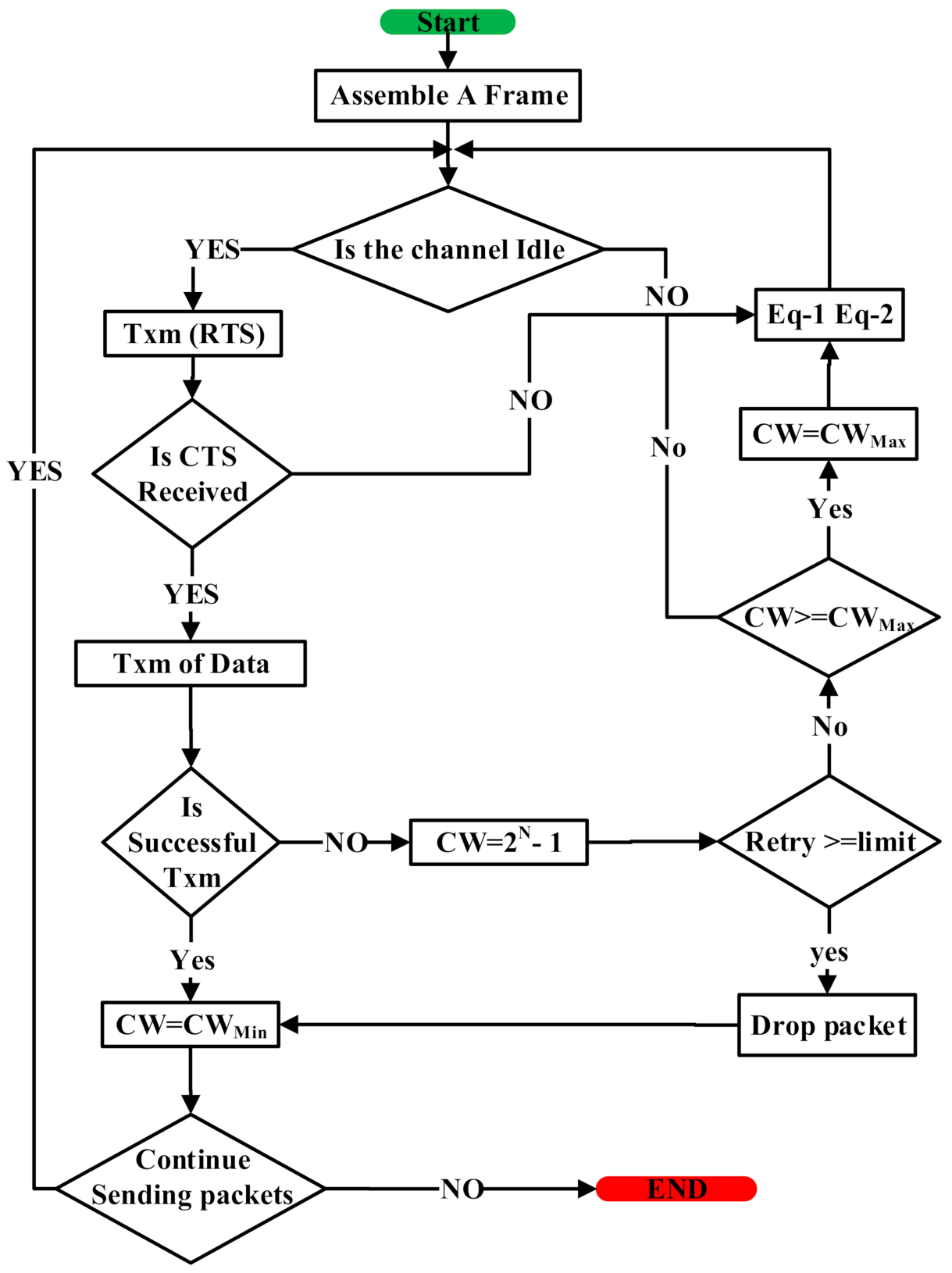

Figure 1. The flowchart of distributed-coordination function (DCF) model in 802.11ac.

Another variant of DCF access mode is known as enhanced distribution channel access (EDCA). It offers distinguished broadcast facilities under four different access classes (ACs) and applies CSMA/CA on each queue in one STA [32]. At the MAC layer, each message is mapped into the ACs, as shown in Table 2. It shows the priority weightage of each access category for both DCF and EDCA channel access modes. EDCA has 4 AC categories named; Voice(VO), Video (VI), Background(BK) and Best efforts(BE). The higher the user priority number, the more chances to access the wireless channel [33]. Each AC will compete for access to the medium in an Arbitration inter-frame space $\left(\mathrm{T}_{\text {AIFS }}\right)$ period in EDCA. The $\mathrm{T}_{\text {AIFS }}$ is expressed by Equation (4) [34]:

$$
\mathrm{T}_{\mathrm{AIFS}}=\alpha \mathrm{T}_{\text {Slot }} \times \mathrm{AIFSN}_{\mathrm{AC}}+\mathrm{SIFS}
$$

where $\mathrm{T}_{\mathrm{AIFS}} \geq 2$ in the case of QoS stations (QSTA) and $\mathrm{T}_{\mathrm{AIFS}} \geq 1$ in the case of QoS access points (QAP). In Equation (4), $\alpha \mathrm{T}_{\text {Slot }}$ represents the duration of a slot, and short interframe space (SIFS) is a short time duration (typically taken as $10 \mu \mathrm{s}$ ) that helps to avoid the collisions, and it is maintained before 
and after clear to send (CTS) frame in the IEEE 802.11 network. $\mathrm{T}_{\mathrm{BO}}$ value for access category $(A C)$ in the case of EDCA is causally chosen from $(0, \mathrm{CW})$ and it is decreased by one slot before the expiry of the $\mathrm{T}_{\text {AIFS }}$. Figure 2 explains this process step by step using a flowchart.

Table 2. The priority weight of each access category in the DCF and EDCA set for 802.11ac

\begin{tabular}{|c|c|c|c|c|c|c|}
\hline Mode & $\mathrm{AC}$ & $\alpha \mathbf{C W}_{\text {Min }}$ & $\alpha \mathrm{CW}_{\mathrm{Max}}$ & $\begin{array}{l}\text { DIFS or } \\
\text { AIFS }\end{array}$ & TXOP & $\begin{array}{c}\text { User } \\
\text { Priority }\end{array}$ \\
\hline \multirow{4}{*}{ EDCA } & BK & $\alpha C W_{\text {Min }}$ & $\alpha \mathrm{CW}_{\operatorname{Max}}$ & 7 & 0 & 1 or 2 \\
\hline & $\mathrm{BE}$ & $\alpha C W_{\mathrm{Min}}$ & $\alpha \mathrm{CW}_{\mathrm{Max}}$ & 3 & 0 & 0 or 3 \\
\hline & VI & $\begin{array}{c}\left(\alpha C W_{\text {Min }}+1\right) \\
\quad \div 2-1\end{array}$ & $\alpha \mathrm{CW}_{\mathrm{Min}}$ & 2 & $3.008 \mathrm{~ms}$ & 4 or 5 \\
\hline & $\mathrm{VO}$ & $\begin{array}{c}\left(\alpha \mathrm{CW}_{\mathrm{Min}}+1\right) \\
\quad \div 4-1\end{array}$ & $\begin{array}{c}\left(\alpha \mathrm{CW}_{\mathrm{Min}}+1\right) \\
\quad \div 2-1\end{array}$ & 2 & $1.504 \mathrm{~ms}$ & 6 or 7 \\
\hline DCF & ALL (AC) & $\alpha \mathrm{CW}_{\mathrm{Min}}$ & $\alpha C W_{\operatorname{Max}}$ & 2 & $\begin{array}{c}\text { Not } \\
\text { Supported }\end{array}$ & $\begin{array}{c}\text { Not } \\
\text { Supported }\end{array}$ \\
\hline
\end{tabular}

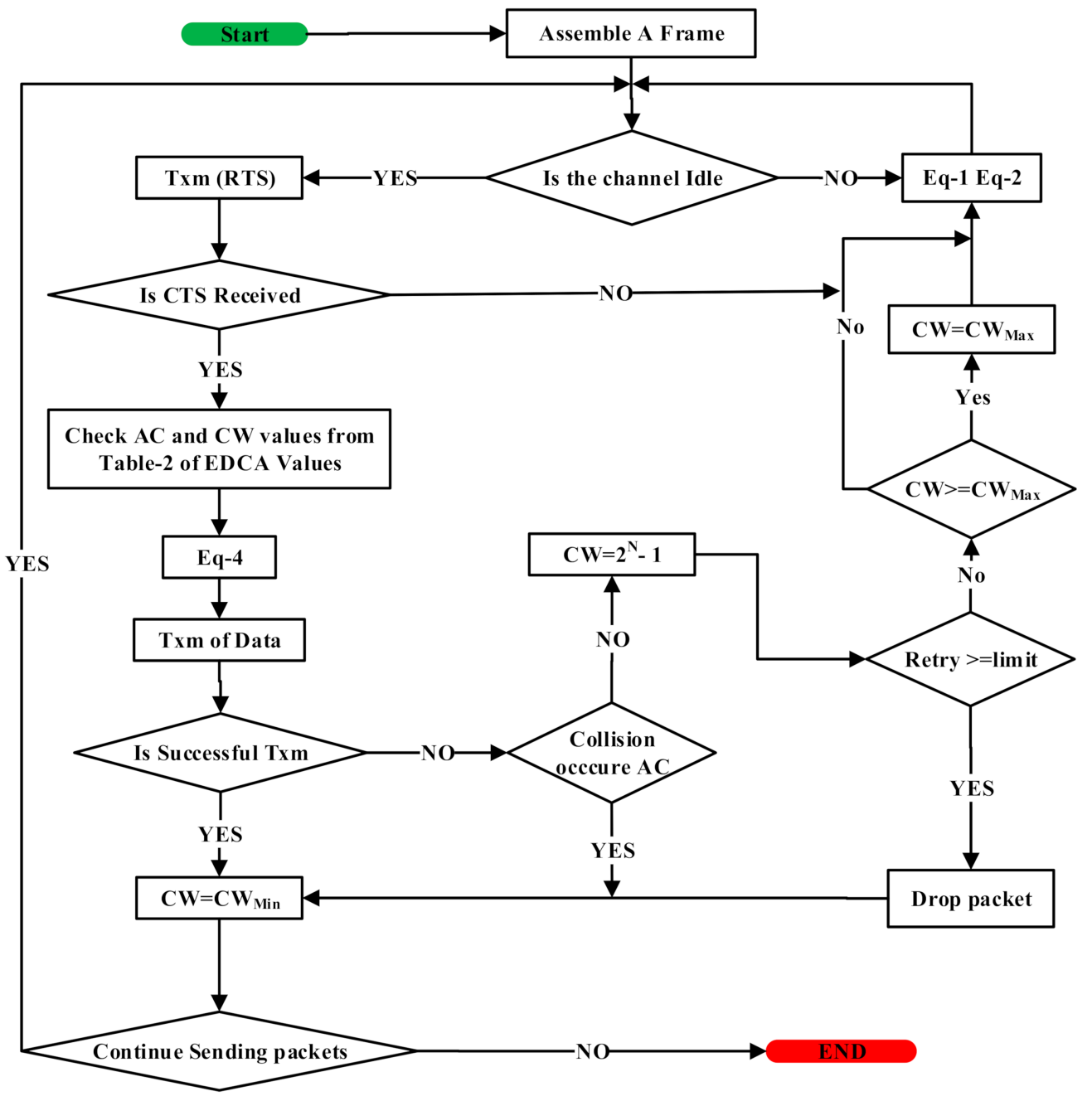

Figure 2. The flowchart of enhanced distributed channel access (EDCA) mode in 802.11ac.

According to the priority mechanism in EDCA, the frames with the highest priority are sent first and the rest have to wait and complete the $\mathrm{BO}$ process with a higher $\mathrm{CW}$ value. When the number of activated ACs starting the $\mathrm{BO}$ process within the same node increases, it causes a virtual collision (VC). At this time, the BO counters are reset and VC management (VCM) handles collision. The VCM guarantees throughput for the higher priority AC but puts the lower priority $\mathrm{AC}$ on a bandwidth 
shortage, which is an unfair allocation of resources. Also, the latest EDCA of 802.11ac supports Transmit Opportunity (TXOP), which is a contention-free access mechanism for one duration of any AC [35].

The typical FiWi access network architecture is shown in Figure 3, where ONUs connect the wireless access points (WAPs) and WAPs connect to wireless users via a wireless channel. The optical line termination (OLT) offers the backbone access to the ONUs [36]. There is a P2MP passive splitter between OLT and ONUs that shares an individual optical fiber channel with many optical fiber channels for ONUs and vice versa (v.v). The communication going from OLT to ONU is called downstream (DS), and when it is going from ONU to OLT it is called upstream (US) in the passive optical network (PON). A dynamic bandwidth allocation (DBA) mechanism acts as an arbitrator for US bandwidth management. The DS frames are used to query ONUs for their bandwidth demand. The DBA process helps to avoid the collisions on the common shared US medium of PON, and additionally, it distributes bandwidth among all the traffic classes of each ONU, identifying each with the help of allocation identity (AllocId). Ten-gigabit PON (XGPON) is an upgraded version of GPON that supports two bitrates (e.g., 2.5 and $10 \mathrm{Gbps}$ ) for the US channel and it supports $10 \mathrm{Gbps}$ for the DS channel. The US and DS communication between OLT and ONU take place in a synchronized manner in $125 \mu$ s duration of frames in XGPON. The DS frame contains a payload and physical control block (PCBD) header. The PCBD contains a bandwidth map (BWMap) for bandwidth allocation of each allocation id that is utilized in the next cycle of US traffic by ONU. There are five different QoS classes for US traffic of XGPON, also termed as transmission containers (TCONTs), which were originally introduced in the broadband passive optical network (BPON) by ITU-T in G984.3 standards [37]. TCONT represents a traffic flow uniquely identified by an allocation id. OLT assigns bandwidth with the help of DBA to all the TCONTs as follows:

(1) Class 1 deals with constant bit rate (CBR) applications that require stringent performance, latency, and delay variation.

(2) Class 2 has efforts to deal with variable bit-rate (VBR) traffic and is suitable for video application that has predefined throughput requirements.

(3) Class 3 offers a guaranteed minimum transmission rate.

(4) Class 4 deals with the best effort (BE) connections.

(5) Class 5 is the combination of all classes.

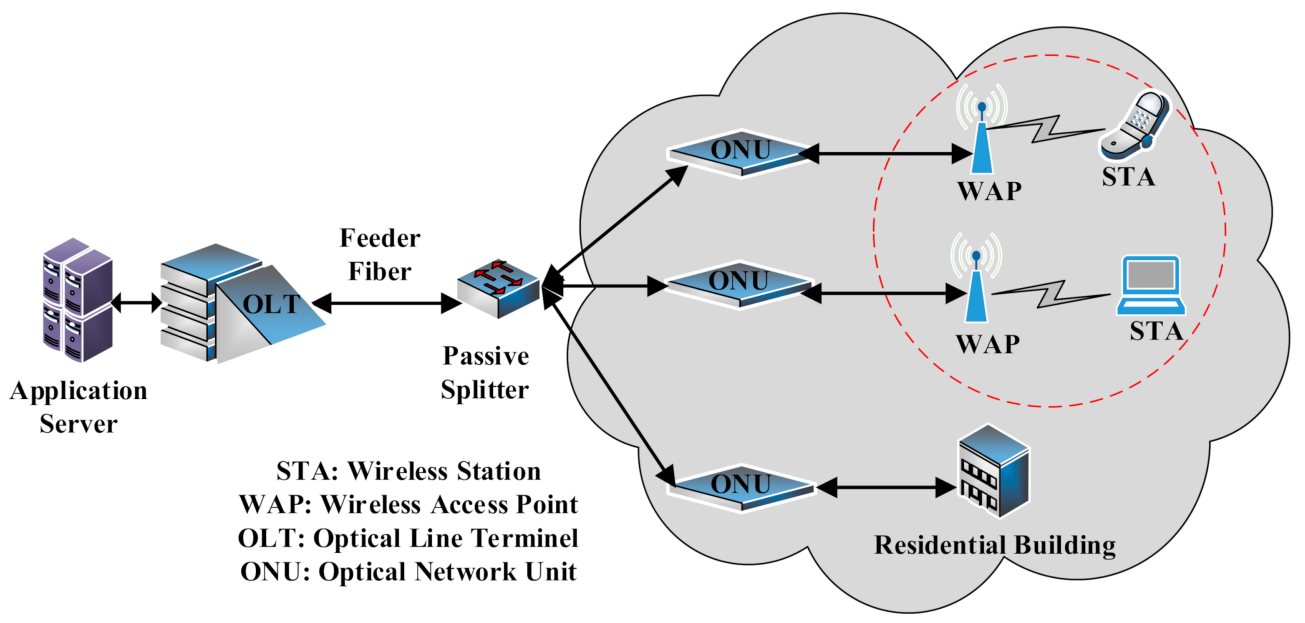

Figure 3. A typical tree topology of the PON network.

\section{Proposed QoS Mapping Schemes for FiWi Testbed}

The prime objective of this study was to investigate the performance issues arisen with the deployment of the FiWi access network based on the XGPON and fifth generation wireless local area 
network (WLAN). Following the recommendations (i.e., G.987.x series) from the Full-Service Access Network (FSAN) group of International Telecommunication Union Telecommunication (ITU-T) [38] and IEEE Standard 802.11ac [39], a comprehensive FiWi simulation testbed was designed in OMNET environment. Considering that both XGPON and 802.11ac are quite complex standards, therefore, we have chosen a built-in 802.11ac module of the INET4.2 framework [40] and used our own XGPON module designed in OMNET, reported in our earlier studies [41,42], and implemented its proper connectivity, in compliance to respective standards, with the 802.11ac module of INET4.2 for this study. Both XGPON and fifth generation WLAN support different traffic classes and require careful mapping of all the traffic classes to achieve service differentiation. The proposed architecture of FiWi with QoS traffic mapping is shown in Figure 4.

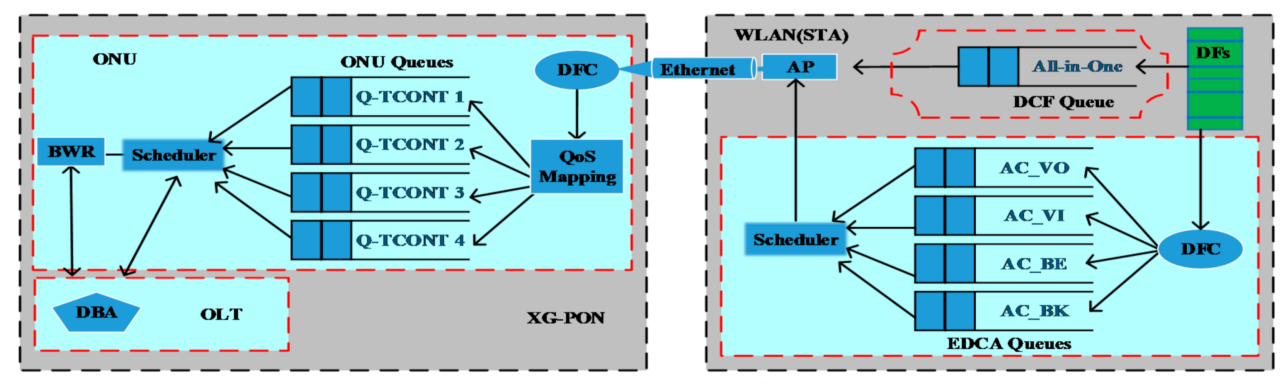

Figure 4. Proposed FiWi architecture with QoS traffic indicators.

The proposed architecture shows the QoS mapping between XGPON and fifth generation $\mathrm{Wi}-\mathrm{Fi} / \mathrm{WLAN}$ for their traffic aggregation. However, XGPON and 5G Wi-Fi/WLAN offer various types of services (ToS) with different delay and bandwidth requirements but they have some common properties and, thus, mapping is possible. For example, T-CONT 1 is similar to the voice (VO) type of WLAN because voice traffic is constant bit rate (CBR) traffic, and T-CONT 1 deals with CBR traffic in XGPON. T-CONT 4 is similar to best-effort (BE) traffic of WLAN.

Figure 5a shows packet classification of the DCF model and EDCA mode of WLAN. The pre-specified QoS mapping scheme is done, where all data frames (DFs) are represented with one single FIFO queue (all-in-one mapping) using the DCF model in STA, and it ensures the provision of QoS in DCF mode. Access points (AP) are also configured with the same QoS configuration and STAs compete with the equivalent bandwidth in DCF mode. By mapping of a class of service (CoS) for each frame in this scheme, no packet classification is required for all frames in the STA and, thus, eliminates the associated overhead, as in FiWi. While, in the EDCA mode, each packet is marked with a user-priority (UP) value that has eight distinct values, i.e., 0 to 7 . After marking the packet, it will then be sent to the ONU unit by an Ethernet link through an AP. For every access category or DSCP, packets are categorized and coupled with a right T-CONT type in each ONU, as shown in Figure 5b.

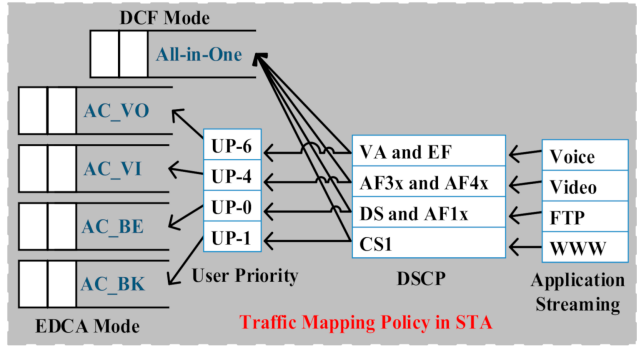

(a) Mapping policy in STA

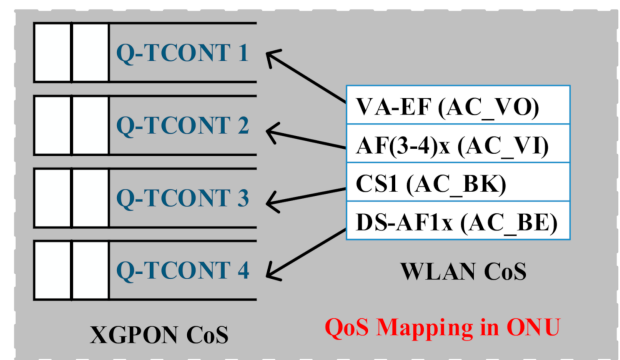

(b) Mapping policy in ONU

Figure 5. (a) Packet classification of DCF and EDCA mode in STA. (b) Packet classification in ONU.

Besides, the dynamic mapping of traffic classes is conducted using the highest cost first (HCF) algorithm inside the data frame arrival process block in the ONU. Algorithm 1 shows the pseudo-code 
of the highest cost first (HCF) algorithm. It is assumed that the highest categorical data packet involves the highest cost because the highest cost packets are delay-sensitive traffic in the network. $\mathrm{T}_{\mathrm{XGPON}}=$ $\{\mathrm{T} 1, \mathrm{~T} 2, \mathrm{~T} 3, \mathrm{~T} 4\}$ represents a set of transfer method of QoS queues in XGPON. We assume the STAs set priority $(\mathrm{P})$ value at the data frame classifier $(\mathrm{DFC})$ block before transmission of the data packet. The cost $(\mathrm{J})$ is calculated according to the transfer method of data packets as per service requirements. Generally, we have J(T1, P) > J(T2, P) > J(T3, P) > J(T4, P). J(T1, P) needs a constant/fixed bandwidth, therefore, its transfer method has the highest priority. The algorithm of the highest cost first mapping dynamically assigns user traffic to the ONU queues according to the cost $(\mathrm{J})$ value. When the maximum cost value is met, the algorithm always searches the specific $P$ value for TCONT queues and saves data into the selected queue according to the transfer method.

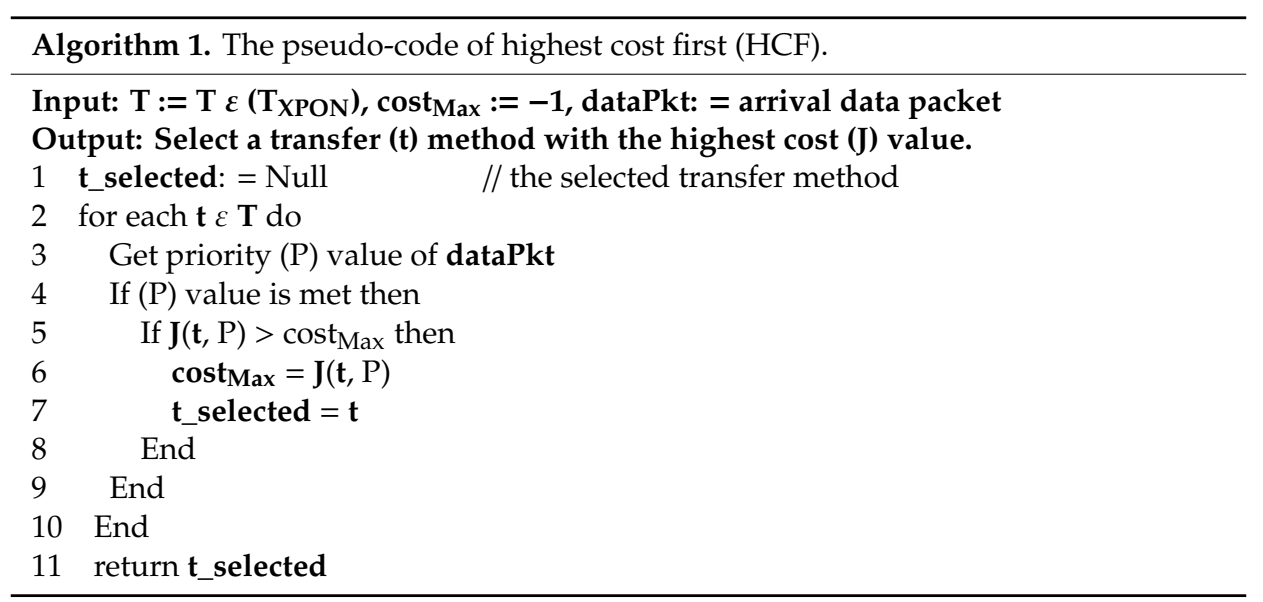

In the algorithm, line 1 defines one variable for keeping the current selected transfer method. The for loop between lines 2 to 10 checks all transfer methods in the set T. Line 3 obtains the P-value of the data packet. Line 4 is executed if $P$ is met. The highest cost value $(t)$ is used to transfer the user traffic $J(t, P)$. Line 5 is used to check condition If $J(t, P)$ value is higher than the current maximum value (costMax). The $J(t, P)$ value is assigned to the current costMax value at line 6 . ( $(t)$ is the currently selected transfer method at line 7 when all the approaches of $\mathrm{T}$ are checked at once. The transfer method will be selected with the highest cost value and packets are then queued in one specific FIFO queue of ONU, and later, the same packet is transmitted via US traffic to the OLT under the DBA controller. The user's data packet is not selected for a specific QoS queue when the selected transfer method (t_selected) is null. The time complexity of the proposed mapping algorithm is $\mathrm{O}(\mathrm{n})$.

During the initialization phase of our testbed, OLT assigns one specific allocation id to a specific TCONT of an ONU. Figure 6 shows the working of our simulation with the help of a flowchart. The first wireless node generates data packets and runs wireless distributed channel schemes as described in the previous section. When a packet arrives at ONU via the wireless access point, then ONU converts each packet according to the QoS mapping algorithm (i.e., highest cost first algorithm), as discussed above in the previous paragraph. 


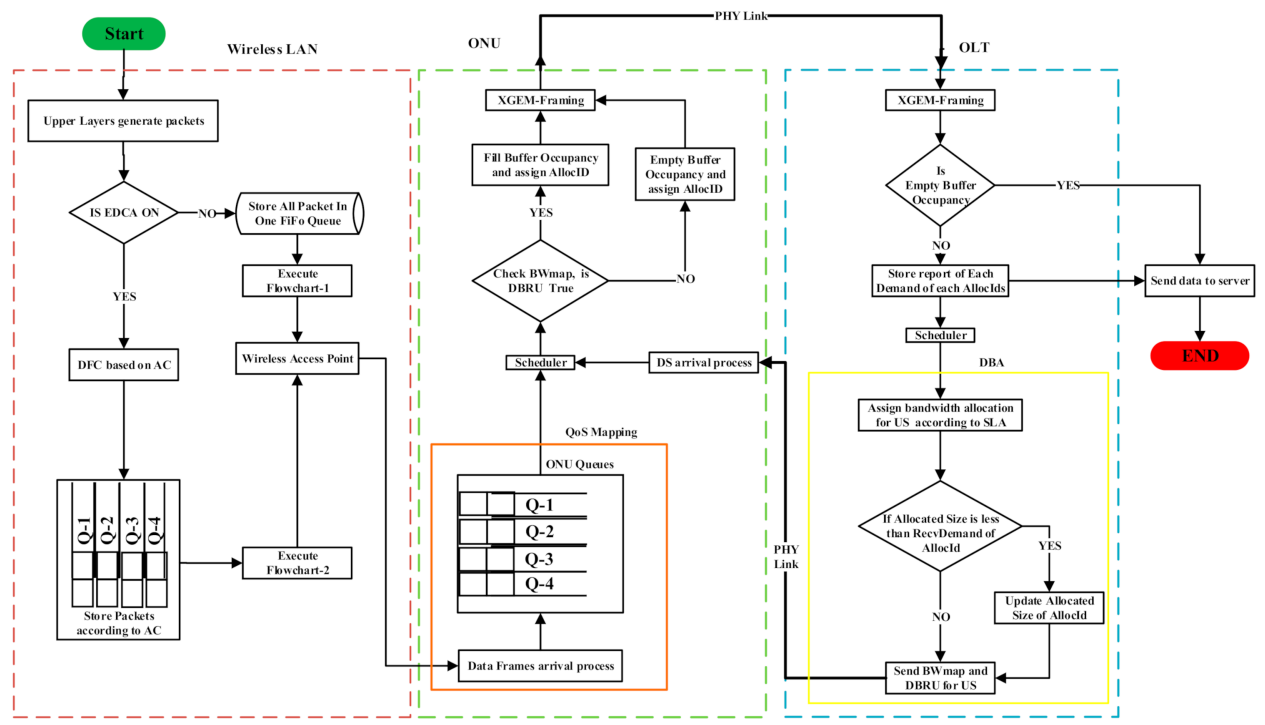

Figure 6. Functional flowchart of proposed FiWi access network.

The ONU scheduler generates upstream traffic after every $125 \mu$ s frame duration, which is also known as the DBA cycle time. ONU fills the buffer occupancy report (BOR) of each TCONT, identified by a unique allocation id, according to the amount of allocated bandwidth to specific TCONT in time, as shown in Equation (5), where $\mathrm{N}(\mathrm{t}, \mathrm{t}+125 \mu \mathrm{s})$ denotes fresh arriving traffic stream into buffer during time interval $t, t+125 \mu$ s for an upstream report (USR) time. Lastly, USR is encapsulated into the XGEM frame and sent to OLT by ONU in US traffic.

$$
\operatorname{USR}(\mathrm{t})=(\operatorname{BOR}(\mathrm{t})+\mathrm{N}(\mathrm{t}, \mathrm{t}+125 \mu \mathrm{s})) \div 125 \mu \mathrm{s}
$$

OLT extracts to the XGEM frame as the XGEM frame arrives at OLT. OLT looks to the buffer-occupancy report and stores it for the next cycle. OLT executes the immediate allocation with a colorless grant (IACG) algorithm as a DBA scheme in every $125 \mu$ s to allocate the grant size of each TCONT or allocation id. IACG [25] utilizes accessible byte counters just as down counters to immediately assign bandwidth grant, sized according to respective TCONT queues depending upon whether the down counters have terminated or not. Also, OLT assigns bandwidth grant sizes to those allocation ids/TCONTs whose request sizes are greater than their current grant sizes assigned by DBA. Lastly, OLT broadcasts BWMap into the DS frame to ONUs.

\section{Simulation Setup and Results}

We have developed a testbed based on XGPON and the pre-existing fifth generation Wi-Fi (802.11ac) module using the INET 4.2 framework and OMNET++5.5 following References [22,43]. The simulation comprises a single OLT, one splitter, and eight ONUs at $20 \mathrm{~km}$ with $10 \mathrm{Gbps}$ US and 10 Gbps DS, as shown in Figure 7. The PON acts as the optical back-end, wherein a 1:1 integrand of ONUs with wireless access points (WAPs) is designed through Ethernet links of 1.2 Gbps line rate. The wireless access points are equipped with both wired and radio interfaces. STAs are connected to the WAP to create single-hop communication, where each STA generates different wireless traffic (i.e., video, voice, best effort, and background) with UDP to the WAP for FiWi traffic. Both WAP and STA use the $40 \mathrm{MHz}$ channel model of Task Group n (TGn) at a $5 \mathrm{GHz}$ frequency band with eight numbers of the spatial stream (NSS). The physical data rate of STA is $1.2 \mathrm{Gbps}$ at the wireless side. STA nodes are randomly distributed in an area of $3000 \times 3000 \mathrm{~m}$. Table 3 summarizes the numerical simulation parameters for the proposed FiWi access network. 


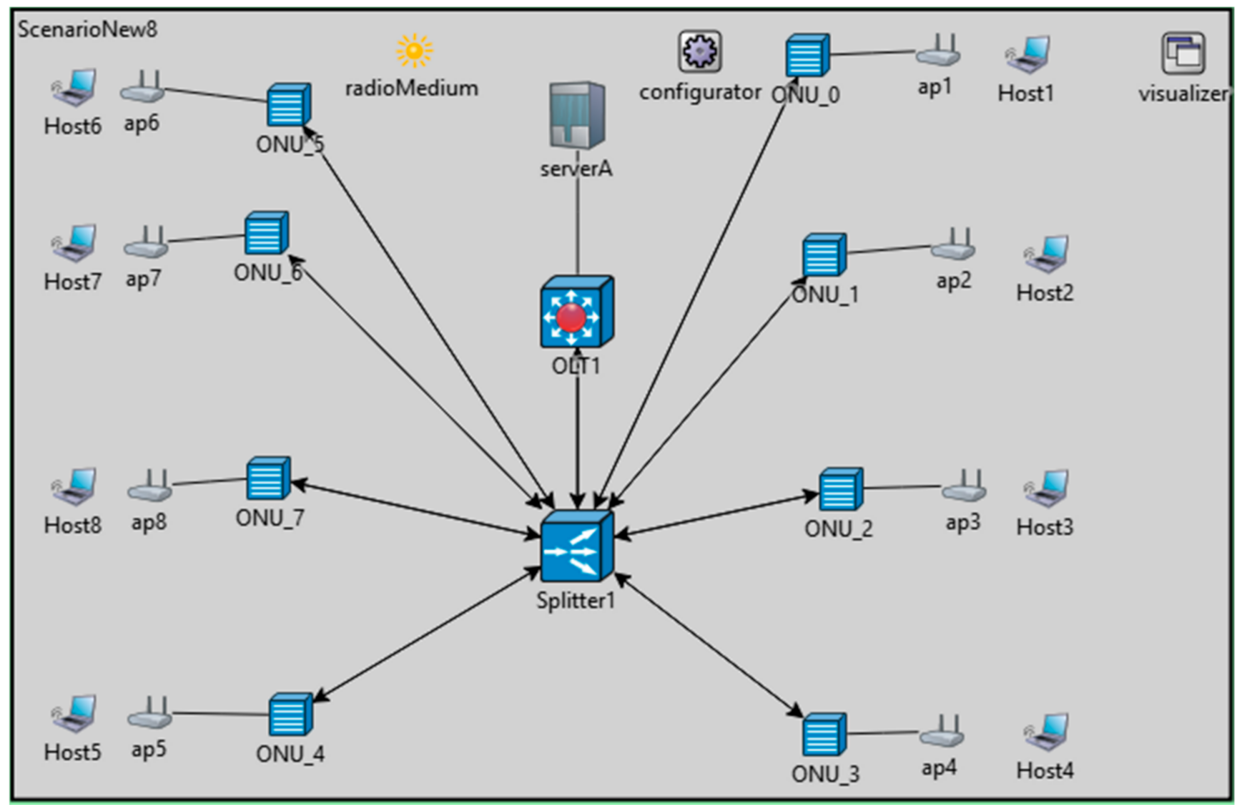

Figure 7. Simulation setup for FiWi network in OMNET++.

Table 3. Simulation parameters.

\begin{tabular}{|c|c|c|}
\hline & Simulation Parameters & Values \\
\hline \multirow{19}{*}{ WLAN } & IEEE 802.11ac MAC Mode & DCF and EDCA \\
\hline & Operating Frequency & $5 \mathrm{GHz}$ \\
\hline & Channel Bandwidth & $40 \mathrm{MHz}$ \\
\hline & Bitrate & $1.2 \mathrm{Gbps}$ \\
\hline & Traffic Model & Poisson Distribution \\
\hline & Modulation (Tx and Rx) & QAM-16 \\
\hline & Forward Error Correction FEC coding rate & $3 / 4$ \\
\hline & Power Tx and Rx & $4 \mathrm{~mW}$ \\
\hline & Rx SNIR Threshold & $10 \mathrm{~dB}$ \\
\hline & Rx Sensitivity & $-86 \mathrm{dBm}$ \\
\hline & BlockAck Supported & True in EDCA \\
\hline & Queue Size & 1000 packets \\
\hline & Max MPDU & 65,535 Octets \\
\hline & RTS Threshold & 100 Bytes(B) \\
\hline & Message Length (BE, BK, VI, and VO) & $\begin{array}{l}\text { Uniform (64 B, } 1472 \text { B), Uniform (128 B, } \\
1024 \text { B), } 1024 \text { B, and } 160 \text { B }\end{array}$ \\
\hline & Transport Protocol & User Datagram Protocol (UDP) \\
\hline & CWmin and CWmax & 3 and 1023 \\
\hline & SlotTime and SifsTime & 9 and $16 \mu \mathrm{s}$ \\
\hline & Number of AP: STA & $8: 8$ \\
\hline \multirow{10}{*}{ XGPON } & Number of OLT:ONU & $8: 8$ \\
\hline & TCONT-1 Bandwidth & $100 \mathrm{Mbps}(\mathrm{ABmin} 1=3000 \mathrm{~B}), \operatorname{SImax}=10)$ \\
\hline & TCONT-2 Bandwidth & $100 \mathrm{Mbps}(\mathrm{ABmin} 2=30,000 \mathrm{~B}), \mathrm{SImax}=10)$ \\
\hline & TCONT-3 Bandwidth Assured & $100 \mathrm{Mbps}(\mathrm{ABmin} 3=15,000 \mathrm{~B}), \operatorname{SImax}=10)$ \\
\hline & TCONT-3 Bandwidth Surplus & $100 \mathrm{Mbps}(\mathrm{ABmin} 3=15,000 \mathrm{~B}), \mathrm{SImax}=10)$ \\
\hline & TCONT-4 Bandwidth & $100 \mathrm{Mbps}(\mathrm{ABmin} 4=30,000 \mathrm{~B}), \mathrm{SImax}=10)$ \\
\hline & ONU Queue Size & $2 \mathrm{MB}$ \\
\hline & DBA Scheme & Immediate Allocation with Colorless Grant \\
\hline & DBA Cycle Time & $125 \mu \mathrm{s}$ \\
\hline & US and DS Line rate & 10 Gbps \\
\hline
\end{tabular}

The wireless station generates UDP traffic using Poisson distribution. We use an exponential function for generating the Poisson distribution-based traffic for all WLAN stations. Equation (6) 
shows the traffic arrival rate $(\lambda)$ computation for the traffic generator configured for each ONU. Where, the physical WLAN data rate (WRate) with the set value of $1.2 \mathrm{Gbps}$ is converted into bytes and then divided by framerate $(\sigma)$ to yield the number of frames for US transmission in the FiWi access network. Framerate $(\sigma)$ is the average value of message length in bytes and has a distinct value for each of 04 classes. Traffic-load varies from 0.1 to 1.0. Since OMNET is a discrete event simulator, the sending interval (SI) event, inter-arrival time, is controlled by a timer and is computed using Equation (7) [44].

$$
\begin{gathered}
\lambda=((\text { WRate } / 8) / \sigma) \times \text { Traffic-Load } \\
\text { SI }=\mathrm{e}^{-1 / \lambda}
\end{gathered}
$$

End-to-End Delay $\left(\mathrm{EE}_{\text {Delay }}\right)$ is an overall delay time that $\mathrm{n}^{\text {th }}$ packets encounter from wireless STA to a server, given in Equation (8), where $\mathrm{AT}_{\mathrm{N}}$ is the arrival time of $n^{\text {th }}$ packet at the destination, GTN is generating time of the $\mathrm{n}^{\text {th }}$ packet, and $\mathrm{TT}_{\mathrm{N}}$ is the transmitting time of the $\mathrm{n}^{\text {th }}$ packet at STA. After STA, the $\mathrm{n}^{\text {th }}$ packet arrives at the wireless access point $(\mathrm{WAP})$, and $\mathrm{APT}_{\mathrm{N}}$ represents the processing time of the $\mathrm{n}^{\text {th }}$ packet at WAP. The WAP forwards the $\mathrm{n}^{\text {th }}$ packet via Ethernet link to the XGPON side and consumes $\mathrm{T}_{\mathrm{XGPON}}$ as the sum of packet processing time from ONU to OLT using Equation (9).

$$
\begin{gathered}
\mathrm{EE}_{\text {Delay }}=\mathrm{AT}_{\mathrm{N}}-\left(\mathrm{GT}_{\mathrm{N}}+\mathrm{TT}_{\mathrm{N}}+\mathrm{APT}_{\mathrm{N}}+\mathrm{T}_{\mathrm{XGPON}}\right) \\
\mathrm{T}_{\mathrm{XGPON}}=\mathrm{PT}_{\mathrm{ONU}}+\mathrm{PT}_{\mathrm{OLT}}
\end{gathered}
$$

Figure 7 shows the $\mathrm{EE}_{\text {Delay }}$ analysis of four concurrent UDP streams, i.e., VO (T1), VI (T2), BK (T3), and BE (T4), in DCF and EDCA mode. Each stream is mapped with different TCONTs of XGPON as explained in Section 3. EE $E_{\text {Delay }}$ in both DCF and EDCA increases from low to high as the load increases, which is absolutely rational, however, compared to DCF, the EDCA delay is lower at higher traffic loads due to the traffic priority mechanism and HCF algorithm. Since DCF uses a single first-in first-out (FIFO) queue to handle all the traffic classes, its $E_{\text {Delay }}$ is higher than the EDCA method in FiWi access network topology for all the T1 to T4 TCONTs. Thus, from Figure 8a, it is evident that the US delay of voice traffic is almost linear in the EDCA model, and in the case of DCF, it is lower at lower load but as the load increases, the delay of voice traffic also increases. Similarly, the video traffic having the second highest priority in EDCA mode, being mapped to T2 with guaranteed bandwidth, also behaves quite the same. Figure $8 \mathrm{~b}$ shows the upstream delay of VI (T2). At lower load, both of the wireless modes are almost linear, but as the load increases, the US-delay for DCF increases exponentially because of the non-priority-based FIFO queueing mechanism of traffic; however, the US delay of VI (T2) remains lower in EDCA mode due to the high-priority traffic queuing mechanism and HCF algorithm. Almost similar behavior is seen for the US delay of BK (T3), where again, EDCA performs better than DCF wireless mode at higher traffic loads. However, the performance of $\mathrm{BE}$ (T4) is different than the VO (T1), VI (T2), and BK (T3) traffic classes, as evident from Figure 8d. The US delay of BE (T4)-DCF is lower at lower traffic load but it increases as traffic load increases. This happens due to the least priority of $\mathrm{BE}$ traffic in EDCA but due to efficient mapping of the HCF algorithm and increased queuing delays in DCF mode at higher loads. Overall, EDCA mode shows up to $93.2 \%, 97.5 \%, 97.6 \%$, and $93.8 \%$ lower US delays compared to DCF mode for VO (T1), VI (T2), BK (T3), and BE (T4) traffic. 


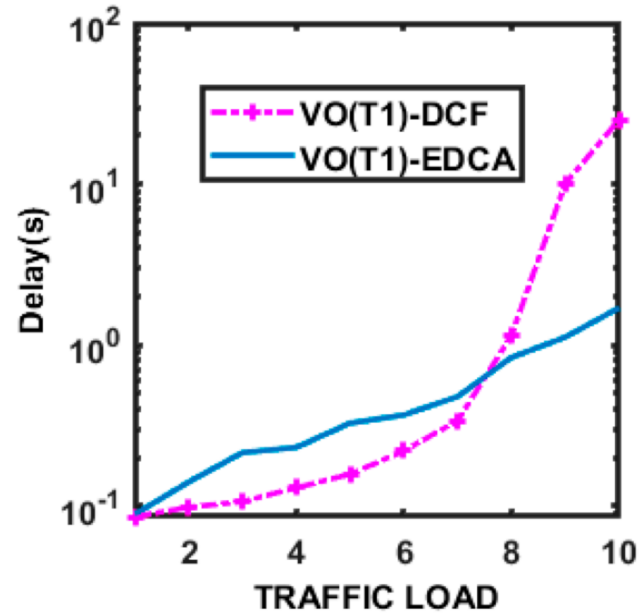

(a) US-delay for VO (T1) under DCF and EDCA

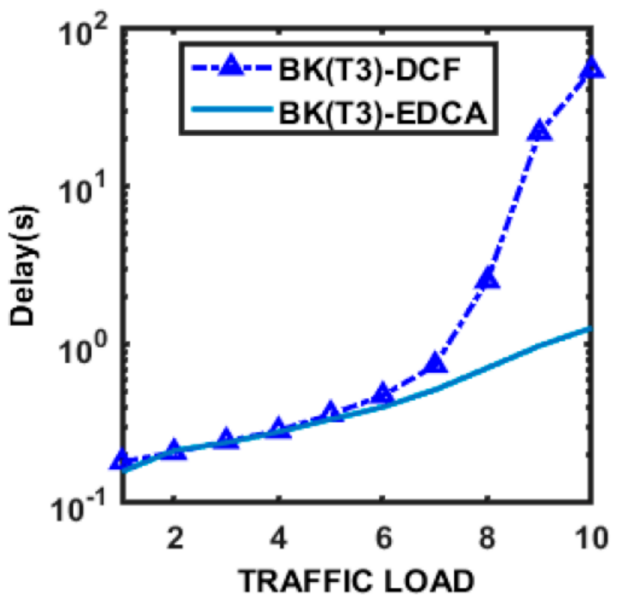

(c) US-delay for BK (T3) under DCF and EDCA

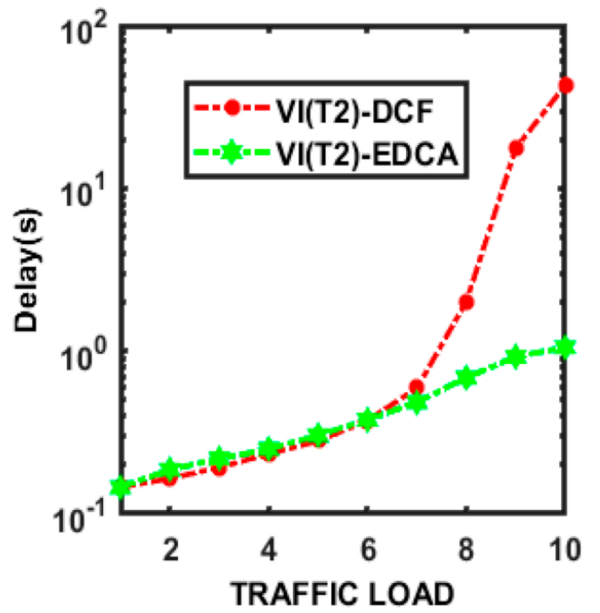

(b) US-delay for VI (T2) under DCF and EDCA

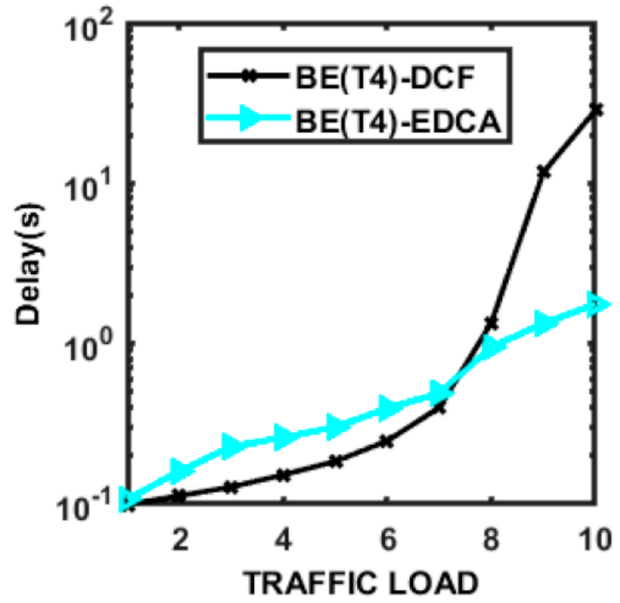

(d) US-delay for BE (T4) under DCF and EDCA

Figure 8. US delay VS traffic load in the FiWi access network: (a) Voice traffic case, (b) video traffic case, (c) background traffic case, and (d) best effort traffic case.

Figure 9 shows the comparative results of overall mean US delay of all traffic classes for our proposed work and earlier work [25] (we call it dGIANT) that did not use the HCF algorithm for traffic mapping and only relied on GIANT DBA. It is clearly evident from Figure 9 that the overall US mean delay of dGIANT DBA is higher compared to our work for both wireless techniques: EDCA and DCF. Initially, the delay in case of DCF of both DBA schemes is lesser, however, it increases as the traffic load increases, due to the same reasons described above. Overall, HCF-DBA shows up to $54.8 \%$ and $53.4 \%$ lower delays for DCF and EDCA modes compared to the dGIANT scheme. 


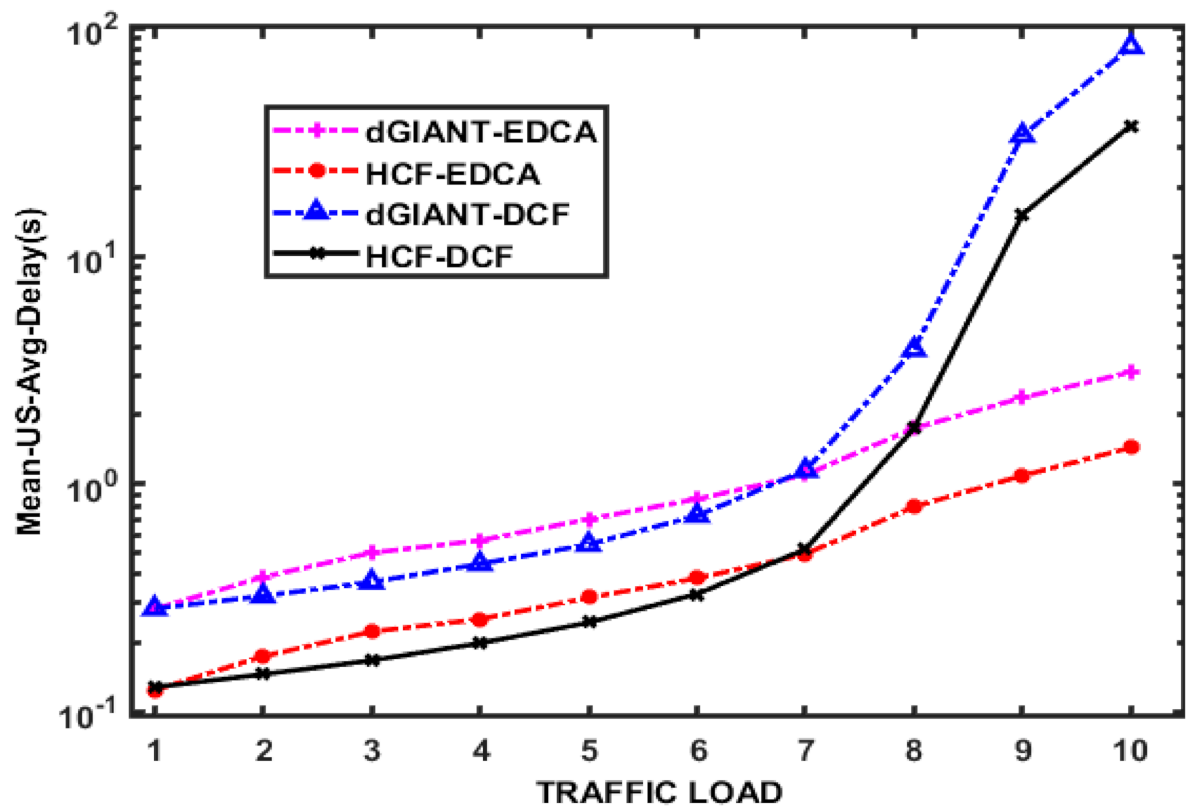

Figure 9. Mean US average delay versus traffic load using DCF and EDCA, with HCF and dGIANT in the FiWi network.

The fairness performance, using the Jain's Fairness Index (JFI), of the proposed scheme was also performed and compared with the dGIANT scheme. The JFI value, termed as $f(y)$, ranges from 0 to 1 , and a higher value implies a tighter relationship between allocated bandwidth and overall allocation, showing a better QoS. The Equations (10) to (12) state the JFI relationship for allocated bandwidth and overall distribution of bandwidth:

$$
\begin{gathered}
f(y)=\frac{\left[\sum_{i=1}^{s} \gamma_{i}\right] 2}{\left.S \times \sum_{i=1}^{s}\left(\gamma_{i}\right)\right)^{2}} \text { if } \gamma_{i} \geq 0 \\
y_{i}=\frac{A B_{i}}{T B_{i}} \text { if } T B_{i}>A B_{i} \\
y_{i}=1, \text { otherwise }
\end{gathered}
$$

where the $\gamma_{i}$ value is expressed as the ratio of allocated bandwidth $\left(A B_{i}\right)$ to the total bandwidth $\left(T B_{i}\right)$ for each ONU at $i$ th load. The term $S$ is the number of contending streams. The performance results of JFI are shown in Figure 10 for dGIANT and HCF schemes versus the traffic load for all the traffic classes for both DCF and EDCA wireless modes. The JFI values in DCF mode are almost the same for all traffic classes due to the FIFO queuing mechanism. However, the HCF algorithm results in a slight performance improvement of $1.2 \%, 1.3 \%$, and $1.5 \%$ for VI (T2), BK (T3), and BE (T4) traffic for the DCF model. However, due to the HCF algorithm, a significant performance improvement was observed in EDCA mode.

The VI (T2) has the lowest CW size in EDCA with the highest priority, thus, its JFI values are higher than the other traffic classes. Figure 10b shows the fairness results for VI (T2), which shows that as the traffic load increases, the JFI values decrease. As VI (T2) is the second highest priority traffic in both standard XGPON and WLAN, therefore, at the XGPON side, the assured bandwidth is reserved for T2 TCONTs. The HCF and IACG combination, referred to here as HCF-DBA, results in higher bandwidth assignment due to efficient traffic mapping between the wireless and optical networks, and the excess bandwidth assignment by the IACG DBA process at the OLT. 


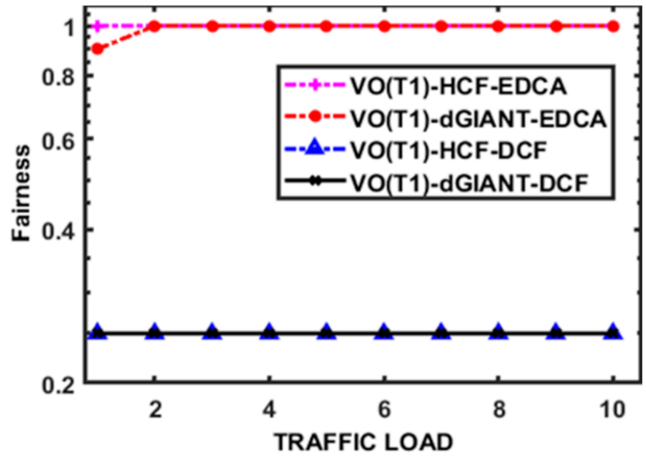

(a) Fairness index versus offer load of $\mathrm{VO}$ (T1)

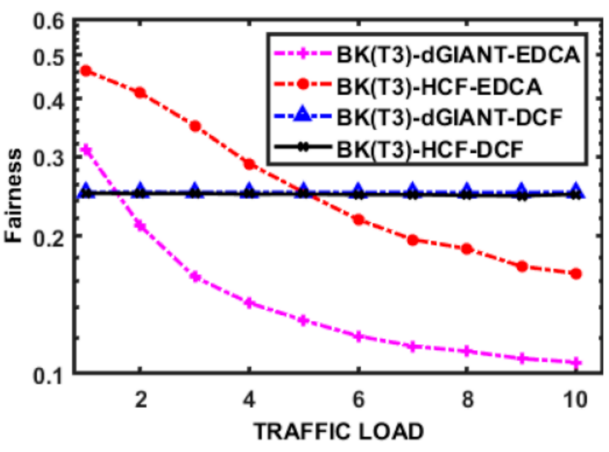

(c) Fairness index versus offer load of BK (T3)

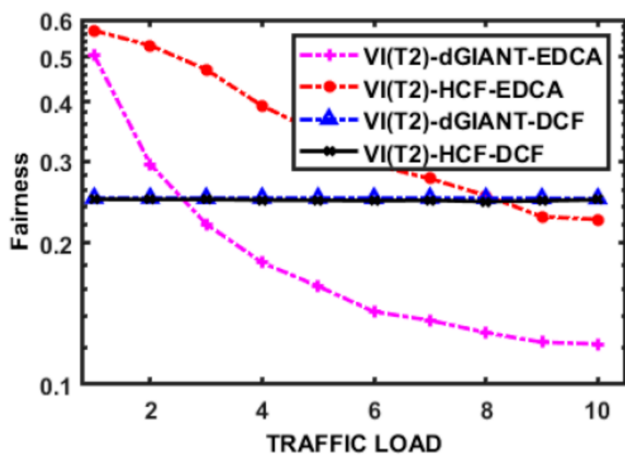

(b) Fairness index versus offer load of VI (T2)

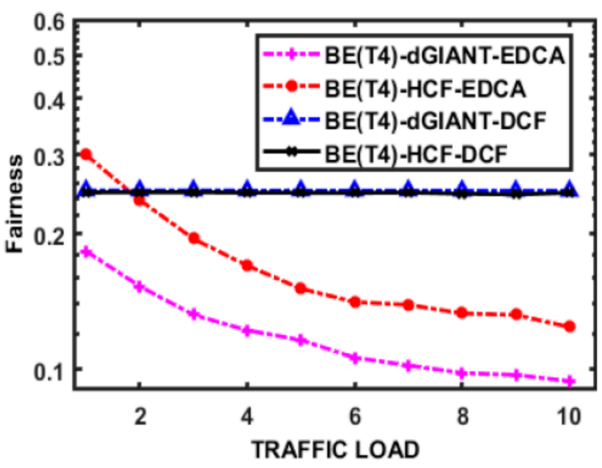

(d) Fairness index versus offer load of BE (T4)

Figure 10. Fairness index versus offer load using DCF and EDCA in the FiWi network: (a) Voice traffic case, (b) video traffic case, (c) background traffic case, and (d) best effort traffic case.

A similar performance boost is also observed for the BK (T3) traffic in EDCA mode, as evident from Figure 10c. The T3 TCONTs have half assured and half non-assured bandwidth in the XGPON DBA process. As the load increases, the JFI index values decrease, but comparatively, the fairness results of HCF are observed to be better than dGIANT. The lowest priority traffic is the BE (T4), but its performance is also significantly improved due to the DCF and IACG combination. Figure 10d presents comparative results which show that dGIANT cannot assign more bandwidth to BE (T4) traffic as compared to IACG, therefore, the JFI values of HCF-DBA are much better than the dGIANT-DBA in our FiWi access network testbed. Overall, a performance improvement of up to $96.1 \%, 90.8 \%$, and $55.5 \%$ for VI (T2), BK (T3), and BE (T4) traffic for the EDCF mode is observed with HCF-DBA compared to the dGIANT scheme.

In order to measure the efficiency of both schemes, we also record the unallocated bandwidth ratio (UBR) at the OLT, as a percentile of unallocated bytes per cycle over total frame bytes available for the US link. Figure 11 shows the UBR for both DBA schemes in both modes. As expected, the UBR is higher for the DCF mode compared to EDCA mode due to single FIFO queuing for traffic. Similarly, as expected, the HCF-DBA performs better than the dGIANT DBA due to the efficient mapping of traffic classes. In all cases, the UBR decreases as the traffic load increases because of increasing traffic demand by the ONUs, which results in higher bandwidth assignment and, thus, lesser unutilized bandwidth. Overall, the HCF-DBA shows up to $65 \%$ and $15 \%$ lower UBR for DCF and EDCA modes compared to the dGIANT scheme in our FiWi access network testbed. 


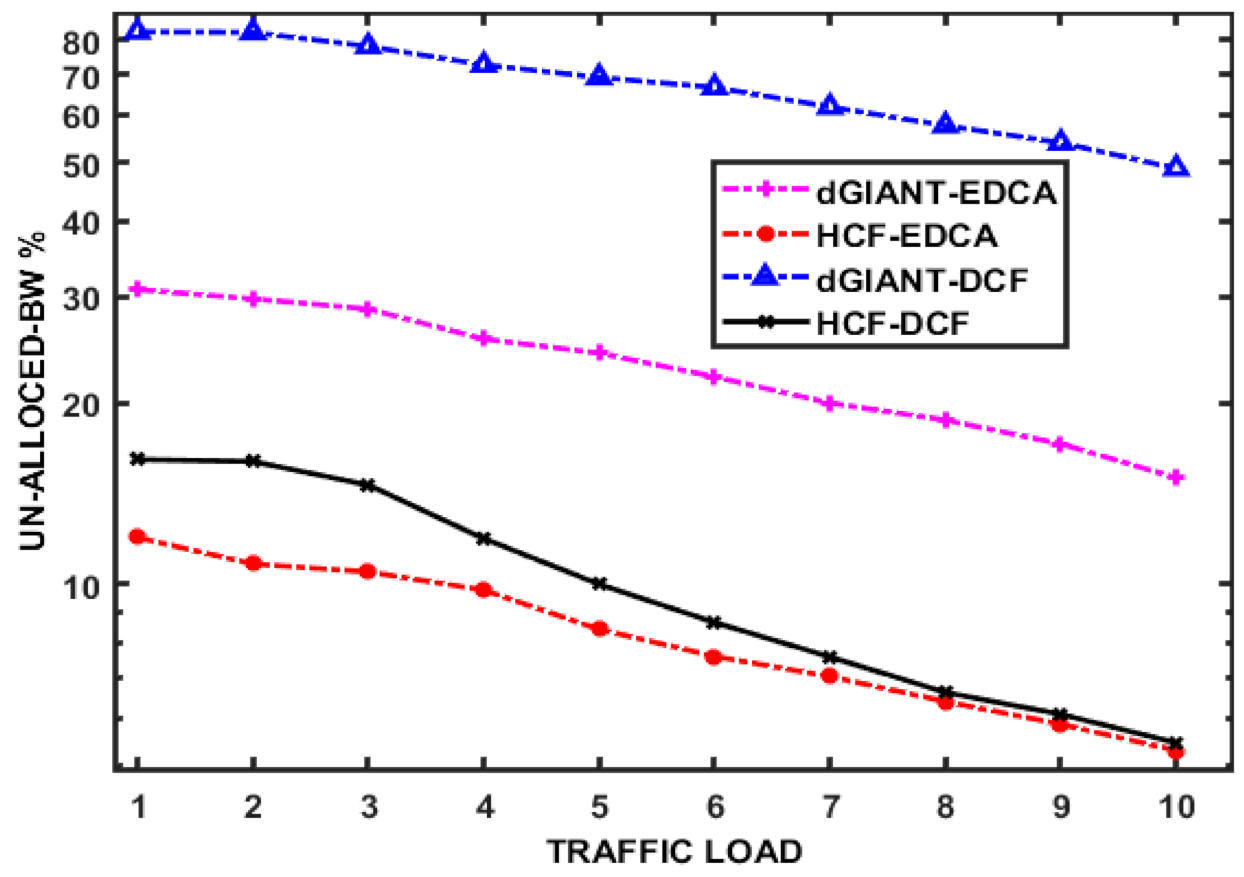

Figure 11. Un-allocated bandwidth versus offer load using DCF and EDCA in the FiWi network.

\section{Conclusions}

This study presented a traffic mapping algorithm for a PON- and WLAN-based FiWi network to improve the Quality of Service (QoS). Both the DCF and EDCA modes were investigated and the comparative performance in terms of mean US delay and bandwidth utilization efficiency was also analyzed. OMNET++ was used to develop a FiWi testbed using XGPON for PON implementation as a front-haul and the fifth generation of WLAN at the access network end. The highest cost first (HCF) algorithm was presented to map the QoS mapping of traffic between the PON data frames, organized according to the HCF algorithm for different types of services of WLAN and XGPON. Our mapping scheme is very flexible and can be useful for any existing or any new integrated architecture of XGPON and WLAN without using any external node. To the best of our knowledge, previously, no such work has been reported which conducted a comprehensive study for the FiWi access network using different channel distributed schemes of 802.11ac with XGPON. The simulation results prove that the HCF algorithm significantly improves the performance of the DBA scheme and leads to a reduction of up to $54.8 \%$ and $53.4 \%$ mean US delays compared to existing work. This happens due to better bandwidth utilization by the HCF-DBA process, which is evident from the UBR results which show $65 \%$ and $15 \%$ lower values for EDCA and DCF modes, respectively. We believe that our research will serve as a base for future studies on the low-latency FiWi access network. Our future plans focus on the adaptive guaranteed access category in EDCA mode for the FiWi access network.

Author Contributions: K.H.M. Implemented the simulation model in Omnet++, did the formal analysis for the results analysis, wrote the paper and funding acquisition. R.A.B., K.A.M. did the supervision, validation and review of first and final version. F.H., A.M. and R.K. did writing-review and editing of the paper. All authors have read and agreed to the published version of the manuscript.

Funding: State Key Laboratory of Information Photonics and Optical Communications (IPOC), Beijing University of Posts and Telecommunications (BUPT).

Acknowledgments: Authors are thankful to the anonymous reviewers for their constructive and logical comments.

Conflicts of Interest: The authors declare no conflict of interest. 


\section{References}

1. Ali, K.; Zhang, Q.; Butt, R.A.; Mohammadani, K.H.; Faheem, M.; Ain, N.U.; Tian, F.; Xin, X. Traffic-Adaptive Inter Wavelength Load Balancing for TWDM PON. IEEE Photonics J. 2019, 12, 1-8.

2. Nazhad, S.H.H.; Shojafar, M.; Shamshirband, S.; Conti, M. An efficient routing protocol for the QoS support of large-scale MANETs. Int. J. Commun. Syst. 2018, 31, e3384. [CrossRef]

3. Shaikh, A.; Vasan, D.; Mohammadani, K.H. Performance Analysis of MANET Routing Protocols-A Comparative Study. Int. J. Comput. Appl. 2013, 83, 1-29. [CrossRef]

4. Madakam, S.; Ramaswamy, R.; Tripathi, S. Internet of Things (IoT): A Literature Review. J. Comput. Commun. 2015, 3, 164-173. [CrossRef]

5. Silva, B.N.; Khan, M.; Han, K. Internet of Things: A Comprehensive Review of Enabling Technologies, Architecture, and Challenges. IETE Tech. Rev. 2017, 4602, 1-16. [CrossRef]

6. Mohammadani, K.H.; Kazi, H.; Shaikh, A.; Channa, I.; Faizullah, S. A Comparison of Homogeneous vs Heterogeneous Choice of Routing Protocols in Integrated Wireless Networks. Eng. Sci. Technol. Int. Res. J 2017, 1, 44-50.

7. Chuenchom, R.; Steffan, A.; Walker, R.G.; Clements, S.J.; Leiba, Y.; Banach, A.; Lech, M.; Stöhr, A. Hybrid Fiber Wireless (HFW) Extension for GPON Toward 5G. Opt. Wirel. Converg. 5G Netw. 2019, 31-55.

8. Sarigiannidis, P.; Sarigiannidis, A.; Moscholios, I.; Zwierzykowski, P. DIANA: A machine learning mechanism for adjusting the TDD uplink-downlink configuration in XG-PON-LTE systems. Mob. Inf. Syst. 2017, 2017, 8198017. [CrossRef]

9. Jones, D. Frequency band selection. U.S. Patent No. 10,757,704, 25 August 2020.

10. Shah, S.Q.A.; Khan, F.Z.; Baig, A.; Iqbal, M.M. A QoS Model for Real-Time Application in Wireless Network Using Software Defined Network. Wirel. Pers. Commun. 2020, 112, 1025-1044. [CrossRef]

11. Lu, C.; Wu, B.; Ye, T. A Novel QoS-Aware A-MPDU Aggregation Scheduler for Unsaturated IEEE802. 11n/ac WLANs. Electronics 2020, 9, 1203. [CrossRef]

12. Prasad Rimal, B.; Maier, M. Fog Computing Enhanced Fiber-Wireless Access Networks in the 5G Era. Opt. Wirel. Converg. 5G Netw. 2019, 249-271. [CrossRef]

13. Yang, M.; Zhou, J. A compact pattern diversity MIMO antenna with enhanced bandwidth and high-isolation characteristics for WLAN/5G/WiFi applications. Microw. Opt. Technol. Lett. 2020, 62, 2353-2364. [CrossRef]

14. Qu, Q.; Li, B.; Yang, M.; Yan, Z.; Yang, A.; Deng, D.J.; Chen, K.C. Survey and Performance Evaluation of the Upcoming Next Generation WLANs Standard-IEEE 802.11ax. Mob. Netw. Appl. 2019, 24, 1461-1474. [CrossRef]

15. Zhou, R.; Li, B.; Yang, M.; Yan, Z.; Zuo, X. QoS-Oriented OFDMA MAC Protocol for the Next Generation WLAN. Xibei Gongye Daxue Xuebao/J. Northwest. Polytech. Univ. 2017, 35, 683-689.

16. Mishra, V.; Upadhyay, R.; Bhatt, U.R.; Kumar, A. DEC TDMA: A Delay Controlled and Energy Efficient Clustered TDMA Mechanism for FiWi Access Network. Optik (Stuttg) 2020, 164921. [CrossRef]

17. Yang, K.; Ou, S.; Guild, K.; Chen, H.H. Convergence of ethernet PON and IEEE 802.16 broadband access networks and its QoS-aware dynamic bandwidth allocation scheme. IEEE J. Sel. Areas Commun. 2009, 27, 101-116. [CrossRef]

18. Shen, G.; Tucker, R. Fixed mobile convergence (FMC) architectures for broadband access: Integration of EPON and WiMax. In Proceedings of the Network Architectures, Management, and Applications V, Wuhan, China, 2-5 November 2007; Wang, J., Chang, G.-K., Itaya, Y., Zech, H., Eds.; SPIE: Bellingham, DC, USA, 2007; Volume 6784, p. 678403.

19. Ahmed, A.; Shami, A. A new bandwidth allocation algorithm for EPON-WiMAX hybrid access networks. In Proceedings of the GLOBECOM-IEEE Global Telecommunications Conference, Miami, FL, USA, 6-10 December 2010.

20. Sesia, S.; Toufik, I.; Baker, M. LTE-The UMTS Long Term Evolution: From Theory to Practice; John Wiley and Sons Ltd.: Hoboken, NJ, USA, 2009; ISBN 9780470742891.

21. Akerele, M.; Al-Anbagi, I.; Erol-Kantarci, M. A Fiber-Wireless Sensor Networks QoS Mechanism for Smart Grid Applications. IEEE Access 2019, 7, 37601-37610. [CrossRef] 
22. Arokkiam, J.A.; Brown, K.N.; Sreenan, C.J. Optimised QoS-Aware DBA mechanisms in XG-PON for upstream traffic in LTE backhaul. In Proceedings of the Proceedings-2016 4th International Conference on Future Internet of Things and Cloud Workshops, W-FiCloud, Vienna, Austria, 22-24 August 2016; Institute of Electrical and Electronics Engineers Inc.: Piscataway Township, NJ, USA, 2016; pp. 361-368.

23. Ou, S.; Yang, K.; Farrera, M.P.; Okonkwo, C.; Guild, K.M. A control bridge to automate the convergence of passive optical networks and IEEE 802.16 (WiMAX) wireless networks. In Proceedings of the 5th Int. Conf. Broadband Commun. Networks, Syst. BROADNETS, London, UK, 8-11 September 2008; Volume 16, pp. 514-521. [CrossRef]

24. Astudillo, C.A.; Da Fonseca, N.L.S. Standard-compliant QoS provisioning scheme for LTE/EPON integrated networks. IEEE Wirel. Commun. 2014, 21, 44-51. [CrossRef]

25. Kaur, R.; Gupta, A.; Srivastava, A.; Chatterjee, B.C.; Mitra, A.; Ramamurthy, B.; Bohara, V.A. Resource Allocation and QoS Guarantees for Real World IP Traffic in Integrated XG-PON and IEEE802.11e EDCA Networks. IEEE Access 2020, 8, 124883-124893. [CrossRef]

26. Dixit, S.; Katiyar, H. Performance of OFDM in time selective Multipath fading channel in 4G Systems. In Proceedings of the 2015 Fifth International Conference on Communication Systems and Network Technologies (IEEE), Gwalior, India, 4-6 April 2015; pp. 421-424.

27. Jiang, L.; Fu, M.L.; Le, Z.C. Hierarchical QoS-aware dynamic bandwidth allocation algorithm for wireless optical broadband access network. In Proceedings of the 2011 International Conference on Electronics, Communications and Control, ICECC 2011-Proceedings, Ningbo, China, 9-11 September 2011; pp. 4329-4332.

28. Hassan, W.H.W.; Idrus, S.M.; King, H.; Ahmed, S.; Faulkner, M. Idle sense with transmission priority in fibre-wireless networks. IET Commun. 2020, 14, 1428-1437. [CrossRef]

29. Mohammadani, K.H.; Memon, K.A.; Memon, I.; Hussaini, N.N.; Fazal, H. Preamble time-division multiple access fixed slot assignment protocol for secure mobile ad hoc networks. Int. J. Distrib. Sens. Netw. 2020, 16, 155014772092162. [CrossRef]

30. Klein, P. 802.11 QoS Overview". In Proceedings of the IEEE Plenary Meeting, November 2008; Volume 38.

31. Coronado, E.; Valero, V.; Orozco-Barbosa, L.; Cambronero, M.E.; Pelayo, F.L. Modeling and simulation of the IEEE 802.11e wireless protocol with hidden nodes using Colored Petri Nets. Softw. Syst. Model. 2020. [CrossRef]

32. Malekzadeh, M. Combination of access categories and frame aggregation schemes for bandwidth efficiency of VHT 802.11ac. J. Eng. Sci. Technol. 2020, 15, 617-635.

33. Mamdouh, M.; Sadek, R.; El Ghoz, H.; El Far, Y. A new dynamic secured IEEE 802.11e AES based system. In Proceedings of the 2017 9th International Conference on Computational Intelligence and Communication Networks (CICN), Girne, Cyprus, 16-17 September 2017; pp. 101-107. [CrossRef]

34. Costa, R.; Lau, J.; Portugal, P.; Vasques, F.; Moraes, R. Handling real-time communication in infrastructured IEEE 802.11 wireless networks: The RT-WiFi approach. J. Commun. Netw. 2019, 21, 319-334. [CrossRef]

35. Nosheen, S.; Khan, J.Y. An Adaptive QoS Based Video Packet Transmission Technique for IEEE802. 11ac WLAN. In Proceedings of the 2019 IEEE 89th Vehicular Technology Conference (VTC2019-Spring) (IEEE), Kuala Lumpur, Malaysia, 28 April-1 May 2019; pp. 1-5.

36. Memon, K.A.; Mohammadani, K.H.; Ain ul, N.; Shaikh, A.; Ullah, S.; Zhang, Q.; Das, B.; Ullah, R.; Tian, F.; Xin, X. Demand forecasting DBA algorithm for reducing packet delay with efficient bandwidth allocation in XG-PON. Electronics 2019, 8, 147. [CrossRef]

37. ITU-T Study Group 15 ITU-T Rec. G.984.3 (03/2008) Gigabit-Capable Passive Optical Networks (G-PON): Transmission Convergence Layer Specification. 2008, pp. 1-146. Available online: https://docplayer.net/4951164-Itu-t-g-984-3-03-2008-gigabit-capable-passive-optical-networks-gpon-transmission-convergence-layer-specification.html (accessed on 1 November 2020).

38. G.987.3: 10-Gigabit-Capable Passive Optical Networks (XG-PON): Transmission Convergence (TC) Layer Specification, 1st ed.; ITU-T: Geneva, Switzerland, 2014.

39. IEEE Computer Society. 802.11ac-2013—Specific Requirements Part 11: Wireless LAN Medium Access Control (MAC) and Physical Layer (PHY) Specifications Amendment 4: Enhancements for Very High Throughput for Operation in Bands below 6 GHz IEEE Computer Society; IEEE: New York, NY, USA, 2013; ISBN 9780738188607.

40. User's Guide-INET 4.2.0 Documentation. Available online: https://inet.omnetpp.org/docs/users-guide/ (accessed on 12 September 2020). 
41. Butt, R.A.; Faheem, M.; Ashraf, M.W.; Idrus, S.M. Sleep assistive dynamic bandwidth assignment scheme for passive optical network (PON). Photonic Netw. Commun. 2018, 36, 289-300. [CrossRef]

42. Butt, R.A.; Faheem, M.; Ashraf, M.W.; Khawaja, A.; Raza, B. Attack-Aware Dynamic Upstream Bandwidth Assignment Scheme for Passive Optical Network. J. Opt. Commun. 2019. [CrossRef]

43. Cisco 802.11ac: The Fifth Generation of Wi-Fi. Cisco.com. 2018, pp. 1-20. Available online: https://www.cisco. $\mathrm{com} / \mathrm{c} / \mathrm{dam} / \mathrm{en} / \mathrm{us} /$ products/collateral/wireless/aironet-3600-series/white-paper-c11-713103.pdf (accessed on 1 November 2020).

44. Butt, R.A.; Idrus, S.M.; Zulkifli, N.; Waqar Ashraf, M. Comprehensive bandwidth utilization and polling mechanism for XGPON. Int. J. Commun. Syst. 2018, 31, e3475. [CrossRef]

Publisher's Note: MDPI stays neutral with regard to jurisdictional claims in published maps and institutional affiliations.

(C) 2020 by the authors. Licensee MDPI, Basel, Switzerland. This article is an open access article distributed under the terms and conditions of the Creative Commons Attribution (CC BY) license (http://creativecommons.org/licenses/by/4.0/). 